Received 00th January 20xx, Accepted 00th January 20xx DOI: $10.1039 / x 0 x \times 00000 x$

\title{
Transition-metal(II) complexes with a tripodal hexadentate ligand, 1,1,1-tris[2-aza-3-(imidazol-4-yl)prop-2-enyl]ethane, exhibiting incomplete total or absolute spontaneous resolution
}

\begin{abstract}
Misaki Matsushima, ${ }^{a}$ Koki Wada, ${ }^{a}$ Yuki Horino, ${ }^{a}$ Kazuma Takahara, ${ }^{a}$ Yukinari Sunatsuki ${ }^{a}$ and Takayoshi Suzuki *ab

Crystal structures and crystallisation behaviours of a series of first-row transition-metal(II) complexes bearing 1,1,1-tris[2aza-3-(imidazol-4-yl)prop-2-enyl]ethane $\left(\mathrm{H}_{3} \mathrm{~L}\right),\left[\mathrm{M}^{\prime \prime}\left(\mathrm{H}_{3} \mathrm{~L}\right)\right] \mathrm{Cl}\left(\mathrm{ClO}_{4}\right)(\mathrm{M}=\mathrm{Mn}, \mathrm{Fe}, \mathrm{Co}, \mathrm{Ni}$ and $\mathrm{Zn})$ were examined. These compounds crystallise in an orthorhombic crystal system with a non-enantiogenic (Sohncke) space group $P 2_{1} 2_{1} 2_{1}$, resulting in spontaneous resolution of the chiral complex cations. Hydrogen bonds between the imidazole $\mathrm{N}-\mathrm{H}$ atoms in the tripodal ligand and chloride anions give enantiomorphic crystals with a homochiral three-dimensional network structure. In order to verify the spontaneous resolution of these compounds, solid-state circular dichroism spectra of the resulting single crystals were measured ( $\mathrm{KBr}$ disk method). Unexpectedly, the observed spectra indicated that imbalanced formation of the enantiomorphic crystals (i.e., left-handed $\Lambda$-form vs. right-handed $\Delta$-form complex cations) in all cases. Moreover, in the cases of $\mathrm{Ni}^{\prime \prime}$ and $\mathrm{Zn}$ " compounds, predominant enantiomorphic crystals formed by spontaneous resolution were always the same (in at least ten of our recrystallisation experiments). These observations suggest that there is a certain (but as yet unknown) factor that affects the predominant deposition of either enantiomorphic crystal when spontaneous resolution takes place from a solution of a racemic mixture in which rapid racemisation occurs.
\end{abstract}

\section{Introduction}

Spontaneous resolution is one of the most convenient and effective methods to resolve a racemic mixture into enantiomers by crystallisation, and it usually gives equal amounts of both enantiomorphic crystals (conglomerates). ${ }^{1}$ Recently, there have been many reports on "total spontaneous resolution" that afforded only one-handed enantiomorphic crystals in a crystallisation experiment (Fig. 1). ${ }^{3-7}$ After in-depth studies about attrition-enhanced resolution and Ostwald ripening, $^{6-10}$ it was well-recognised that total spontaneous resolution of some organic compounds was successfully achieved under catalytic racemisation. Moreover, in the cases of some transition-metal complexes, no catalysis was required for these phenomena because a rapid ligand-exchange could lead the racemisation reaction in solution. ${ }^{5,11}$ Although total spontaneous resolution gives a pure enantiomer (or onehanded enantiomorphic crystals) in $100 \%$ yield, it is not possible

\footnotetext{
Graduate School of Natural Science and Technology, Okayama University, Okayama 700-8530, Japan.

b. Research Institute for Interdisciplinary Science, Okayama University, Okayama 700-8530, Japan. E-mail: suzuki@okayama-u.ac.jp.

Electronic Supplementary Information (ESI) available: CCDC 1952407-1952412. Temperature-dependent magnetic susceptibility data of compounds 1-4; IR and UVvis absorption spectra of compounds 1-5; ORTEP drawings of compounds 3-5 and 2A; a packing diagram of compound $\mathbf{2 A}$; a $\mathrm{CD}$ spectrum of $\mathbf{2}$ in $\mathrm{MeOH}$; the observed and simulated PXRD spectra of compounds 1-5 (except for 3); preparation of sample disk for solid-state $C D$ measurement; tables of crystallographic data and selected structural parameters. See DOI: 10.1039/x0xx00000x
}

to predict which enantiomer will be obtained in a specific crystallisation experiment; formation of either enantiomer takes place randomly. Here, we propose a hypothetical example in which either enantiomer is (or one-handed enantiomorphic crystals are) always obtained exclusively and predictably. This phenomenon may be referred to as "absolute spontaneous resolution" (Fig. 1), and it could be a perfect method for absolute asymmetric synthesis. In this study, we investigate a possibility of total or absolute spontaneous resolution using some transition-metal(II) complex salts containing a certain tripodal hexadentate Schiff base-type ligand.

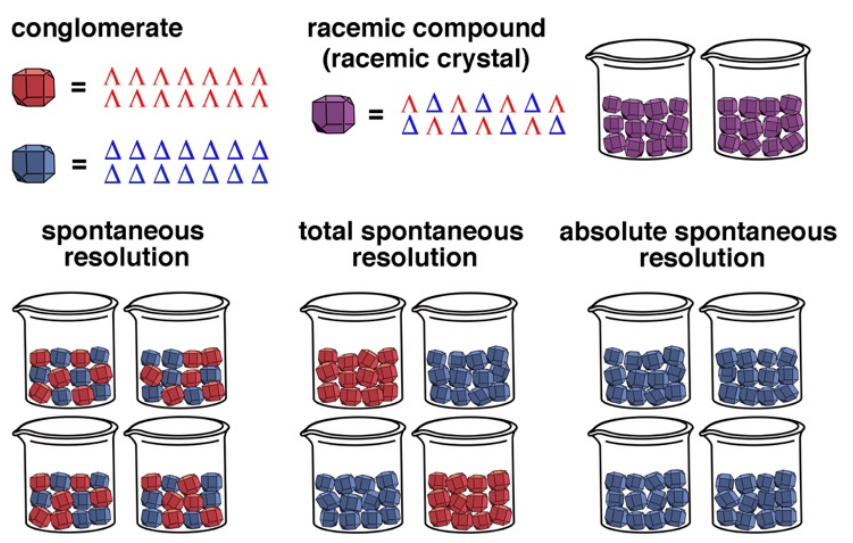

Fig. 1 Definition of total and absolute spontaneous resolution, together with (normal) spontaneous resolution and formation of racemic compounds (racemic crystals). 
Tripodal multidentate ligands are versatile and successfully utilized in many aspects of coordination chemistry. ${ }^{6,12-23}$ In particular, those of tris(Schiff base)-type compounds derived from tripodal triamine precursors and formylimidazoles ${ }^{13-17,22}$ have been widely used for the construction of functional coordination compounds because these ligands effectively cover the central metal ion and induce chirality around it. Furthermore, because the coordinated imidazole (or imidazolato) groups can form intermolecular hydrogen bonds or further coordination bonds with a second metal ion, these complexes have been successfully utilized as building blocks for the selective formation of di- or polynuclear homo- and heterometallic complexes and for functional metal-organic frameworks (MOFs). For example, the formation of heterometallic cage complexes based on the coordination of the imidazolato groups of the tripodal ligand has recently been reported. ${ }^{16}$ Moreover, MOFs constructed from tripodal imidazole-based complexes by intermolecular hydrogenbonding interaction exhibit chiral recognition of the guest molecules in the cavity. ${ }^{17}$ For the precursor tripodal triamines, tris(2-aminoethyl)amine is usually utilised because it is easily accessible. However, similar tripodal amines such as 1,1,1tris(aminomethyl)ethane (tame) $)^{19-22}$ is also an interesting precursor. In an earlier work, we prepared some series of mono-, di-, tri- and tetranuclear metal complexes derived from the tripodal hexa- or nonadentate tame-based Schiff base ligands and then characterised the interesting structural and physical properties of these complexes. ${ }^{19,20}$ However, we noted that for transition-metal complexes of 1,1,1-tris[2-aza-3-(imidazol-4yl)prop-2-enyl]ethane, which is derived from tame and 4formylimidazole $\left(\mathrm{H}_{3} \mathrm{~L}\right.$ : Scheme 1$)$, only one report has been published on the iron(II) complex, $\left[\mathrm{Fe}\left(\mathrm{H}_{3} \mathrm{~L}\right)\right]\left(\mathrm{ClO}_{4}\right)_{2} \bullet 0.5 \mathrm{H}_{2} \mathrm{O} .^{22}$

We now report on the preparation, crystal structures and crystallisation behaviours of mononuclear $\mathrm{Mn}^{\prime \prime}, \mathrm{Fe}^{\text {", }} \mathrm{Co}^{\prime \prime}, \mathrm{Ni}^{\prime \prime}$ and $\mathrm{Zn}^{\prime \prime}$ complexes containing $\mathrm{H}_{3} \mathrm{~L}$. The crystal structures of these compounds differ from the abovementioned Fe" complex salt (reported by Gütlich et al. ${ }^{22}$ ) because the counter ions are a combination of $\mathrm{Cl}^{-}$and $\mathrm{ClO}_{4}^{-}:\left[\mathrm{M}\left(\mathrm{H}_{3} \mathrm{~L}\right)\right] \mathrm{Cl}\left(\mathrm{ClO}_{4}\right)$. Interestingly, these compounds exhibit spontaneous resolution; they crystallise in the non-enantiogenic Sohncke space group ${ }^{24}$ $P 2{ }_{1} 2_{1} 2_{1}$ with $Z=4$. They also demonstrate an unusual crystallisation behaviour, as observed by solid-state circular dichroism (CD) spectroscopy.

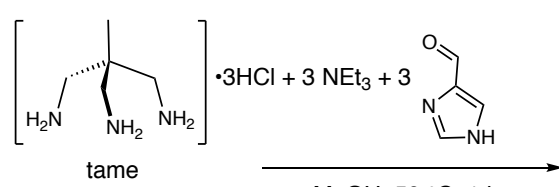

$\mathrm{MeOH}, 50^{\circ} \mathrm{C}, 1 \mathrm{~h}$

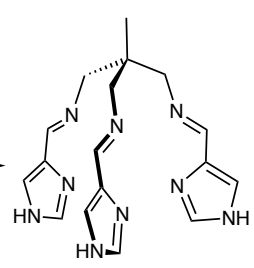

$\mathrm{H}_{3} \mathrm{~L}$
Scheme 1 Preparation of a tripodal hexadentate ligand $\mathrm{H}_{3} \mathrm{~L}$.

\section{Results and discussion}

Synthesis and characterisation of complexes
We prepared the ligand $\mathrm{H}_{3} \mathrm{~L}$ in situ by the reaction of 1,1,1tris(aminomethyl)ethane tri(hydrochloride) (tame $\bullet 3 \mathrm{HCl}$ ), triethylamine ( 3 equiv), and 4 -formylimidazole ( 3 equiv) in methanol at $50^{\circ} \mathrm{C}$ for $1 \mathrm{~h}$ (Scheme 1). This was followed by the addition of a methanol solution of a stoichiometric amount of $\mathrm{M}\left(\mathrm{ClO}_{4}\right)_{2} \bullet 6 \mathrm{H}_{2} \mathrm{O}\left(\mathrm{M}=\mathrm{Mn}\right.$ ", $\mathrm{Fe}^{\prime \prime}, \mathrm{Co}^{\prime \prime}, \mathrm{Ni}^{\prime \prime}$ or $\left.\mathrm{Zn}^{\prime \prime}\right)$ to the resulting ligand solution. The reaction mixture was stirred for several hours at room temperature, whereafter a precipitate of the respective products $\mathbf{1 - 5}$ was obtained. Synthesis of the Co" complex $\mathbf{3}$ was performed in an inert atmosphere to prevent autoxidation to the corresponding Co"l' complex. Single crystals or microcrystals, suitable for analysis by X-ray diffraction (XRD), magnetic measurements and spectroscopic studies (vide infra), were obtained by recrystallisation from a methanol solution by slow evaporation.

The resulting compounds were characterised by elemental analysis, magnetic susceptibility measurements, IR and UV-vis absorption spectroscopy, as well as single-crystal X-ray diffraction (SC-XRD) analysis, which indicated that all crystalline samples of products $\mathbf{1 - 5}$ had the chemical formula $\left[\mathrm{M}\left(\mathrm{H}_{3} \mathrm{~L}\right)\right] \mathrm{Cl}\left(\mathrm{ClO}_{4}\right)\{\mathrm{M}=\mathrm{Mn}(1), \mathrm{Fe}(2), \mathrm{Co}(3), \mathrm{Ni}(4)$ and $\mathrm{Zn}(5)\}$. In addition, phase purity of these crystals was confirmed by SCXRD and powder X-ray diffraction (PXRD) methods (vide infra). Temperature-dependence of the magnetic susceptibility of compounds 1-4 are shown in Fig. S1, which indicates that the $\mathrm{Ni}^{\prime \prime}$ compound (4) is paramagnetic $\left(\chi_{\mathrm{M}} T=1.20 \mathrm{~cm}^{3} \mathrm{~mol}^{-1} \mathrm{~K}\right.$ at $300 \mathrm{~K}$ ). The $\mathrm{Mn}^{\prime \prime}$ and Co" compounds (1 and $\mathbf{3}$ ) are in the highspin states $\left(\chi_{\mathrm{M}} T=4.44\right.$ and $3.01 \mathrm{~cm}^{3} \mathrm{~mol}^{-1} \mathrm{~K}$ at $300 \mathrm{~K}$, respectively), while the $\mathrm{Fe}^{\prime \prime}$ compound (2) is in the diamagnetic low-spin state $\left(\chi_{M} T=0.10 \mathrm{~cm}^{3} \mathrm{~mol}^{-1} \mathrm{~K}\right.$ at $\left.300 \mathrm{~K}\right)$. The latter result is consistent with that reported for the $\left(\mathrm{ClO}_{4}\right)_{2}$ salt of the $\mathrm{Fe}$ "I complex. $^{22}$ In the IR spectra (Fig. S2) all compounds show a strong $v(\mathrm{C}=\mathrm{N})$ bond around $1,635 \mathrm{~cm}^{-1}$ and strong bands due to $\mathrm{ClO}_{4}^{-}$anion around $1,100 \mathrm{~cm}^{-1}$. The spectral pattern of the $\mathrm{Fe}$ compound (2) is slightly different from those of the others, presumably owing to its spin-state. In the UV-vis absorption spectra (Fig. S3) all complexes exhibit a characteristic intense absorption bands around $250 \mathrm{~nm}$. In addition, the $\mathrm{Fe}^{\prime \prime}$ compound (2) gives two intense $\left(\varepsilon \approx 10,000 \mathrm{~mol}^{-1} \mathrm{dm}^{3} \mathrm{~cm}^{-1}\right)$ MLCT bands at 470 and $505 \mathrm{~nm}$. The Co" and Ni" compounds ( 3 and 4) show a weak $d-d$ transition band at 465 and $535 \mathrm{~nm}$, respectively.

Single-crystal X-ray analysis (Table S1) confirmed that the compounds 1-5 crystallised in an orthorhombic and a nonenantiogenic (Sohncke) space group $P 2_{1} 2_{1} 2_{1}$ with $Z=4$ and were isomorphous. This is indicative of the spontaneous resolution of the enantiomeric complexes, originating from the synchronised skew coordination of three chelate arms of the tripodal ligand, as shown in Figs. 2 and S4. The absolute structures of the analysed complexes of $\mathrm{Mn}(\mathbf{1}), \mathrm{Ni}(\mathbf{4})$ and $\mathrm{Zn}(5)$ were $\Delta$-form, and those of Fe (2) and Co (3) were $\Lambda$-form. 


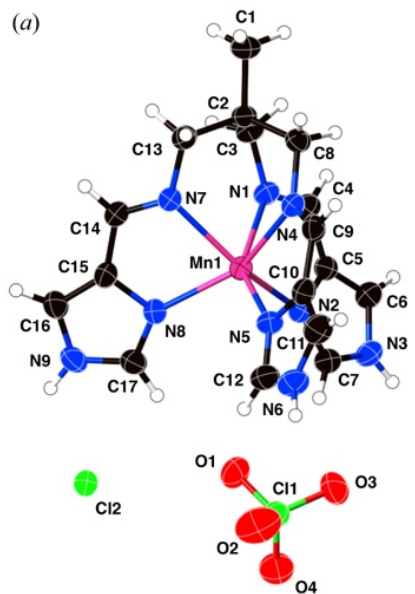

(b)

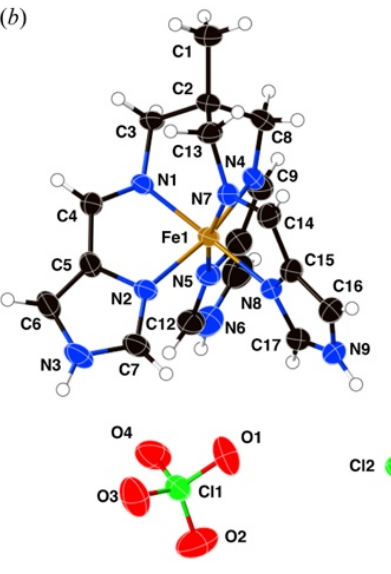

Fig. 2 An ORTEP view (50\% probability level) of $(a)\left[\mathrm{Mn}\left(\mathrm{H}_{3} \mathrm{~L}\right)\right] \mathrm{Cl}\left(\mathrm{ClO}_{4}\right)(\mathbf{1})$ and $(b)$ $\left[\mathrm{Fe}\left(\mathrm{H}_{3} \mathrm{~L}\right)\right] \mathrm{Cl}\left(\mathrm{ClO}_{4}\right)(\mathbf{2})$

Comparison of the structural parameters among the series of complexes are listed in Table 1. In this table three parameters related to one another by pseudo three-fold rotation in each complex cation are listed collectively, but not averaged in order to clarify the degree of their deviations. It is obvious that, while compounds 1-5 are isomorphous, the molecular structures of the complex cations exhibit distinct differences. The bond lengths and angles of the tripodal ligand are not altered by the coordinated metal(II) ion, but the $\mathrm{M}-\mathrm{N}(\mathrm{a}$ : imine) and $\mathrm{M}-\mathrm{N}(\mathrm{b}$ : imidazole) bond lengths become longer in the order of $\mathbf{2}$ ( $\mathrm{Fe}^{\prime \prime}$ : LS) $<\mathbf{4}\left(\mathrm{Ni}^{\prime \prime}\right)<\mathbf{3}$ (Co": HS) $\leq \mathbf{5}\left(\mathrm{Zn}^{\prime \prime}\right)<\mathbf{1}\left(\mathrm{Mn}^{\prime \prime}\right.$ : HS), presumably depending on the ionic radii of metal(II) ions. The Fe" complex is closest to an ideal octahedral geometry, as the chelate bite angles of $\mathrm{N}(\mathrm{a})-\mathrm{M}-\mathrm{N}(\mathrm{b})$ are $80.7(1)-81.0(1)^{\circ}$ and the mutually trans bond angles of $\mathrm{N}(\mathrm{a})-\mathrm{M}-\mathrm{N}\left(\mathrm{b}^{\prime}\right)$ are $163.4(1)-165.7(1)^{\circ}$ These bond angles become smaller and the angular distortions around the metal centre become larger in the order of $\mathrm{Fe}^{\prime \prime}<\mathrm{Ni}^{\prime \prime}$ $<\mathrm{Co}^{\prime \prime} \leq \mathrm{Zn}$ " < Mn" (Table 1). In the Mn" complex, the mutually trans $\mathrm{N}(\mathrm{a})-\mathrm{M}-\mathrm{N}\left(\mathrm{b}^{\prime}\right)$ angles are only $145.07(8)-149.06(8)^{\circ}$, and the angles of $\mathrm{N}(\mathrm{b})-\mathrm{M}-\mathrm{N}\left(\mathrm{b}^{\prime}\right)$ between the coordinating imidazole $\mathrm{N}$ atoms become as large as $96.91(7)-101.13(8)^{\circ}$. More interestingly, in the Fe" complex the Fe-N(a) bonds (1.935(3)1.951(3) $\AA$ ) are shorter than the $\mathrm{Fe}-\mathrm{N}(\mathrm{b})$ bonds (1.974(3)1.990(3) Å), while the $\mathrm{Mn}^{\prime \prime}$ and $\mathrm{Zn}$ " complexes exhibit opposite tendency: e.g., in the $M n^{\prime \prime}$ complex the $\mathrm{Mn}-\mathrm{N}(\mathrm{a})$ bonds $(2.260(2)-2.292(2) \AA)$ are longer than the $\mathrm{Mn}-\mathrm{N}(\mathrm{b})$ bonds $(2.206(2)-2.217(2) \AA)$. In the Co" and $\mathrm{Ni}^{\prime \prime}$ complexes the $\mathrm{M}-\mathrm{N}(\mathrm{a})$ and $\mathrm{M}-\mathrm{N}(\mathrm{b})$ bond lengths are nearly equal. It is concluded that the $\mathrm{M}-\mathrm{N}(\mathrm{a}$ : imine) bond receives larger influence from the coordinated metal(II) ion than the $\mathrm{M}-\mathrm{N}(\mathrm{b}$ : imidazole) bond does. Even in the abovementioned difference in the bond lengths and angles among the complex cations, the torsion angles of the tripodal $\mathrm{H}_{3} \mathrm{~L}$ ligand coordination, $\mathrm{M}-\mathrm{N}(\mathrm{a})-\mathrm{C}(\mathrm{c})-\mathrm{C}(\mathrm{b})$ (see: Table 1 , footnote), which are the origin of the chirality in the complex cations, are almost the same as one another.

\section{Comparison of crystal structures of the iron(II) complex salts}

Gütlich et al. have reported the crystal structure and physical properties of $\left[\mathrm{Fe}\left(\mathrm{H}_{3} \mathrm{~L}\right)\right]\left(\mathrm{ClO}_{4}\right)_{2} \bullet 0.5 \mathrm{H}_{2} \mathrm{O}(2 \mathrm{~A})$, which was prepared by a reaction of $\mathrm{Fe}\left(\mathrm{ClO}_{4}\right)_{2}$, tame, and 4-formylimidazole (1:1:3 molar ratio) in water. ${ }^{22}$ The compound $\mathbf{2 A}$ crystallised in the triclinic space group $P \overline{1}$ with $Z=2$, indicating that crystals of the racemic compound were deposited (Fig. 1). This is in stark contrast to our compound $\mathbf{2}$, which crystallises as a conglomerate in a non-enantiogenic (Sohncke) space group $P 2{ }_{1} 2{ }_{1} 2_{1}$.

Because the two synthetic procedures used for 2 (the $\mathrm{Cl}\left(\mathrm{ClO}_{4}\right)$ salt) and $2 \mathrm{~A}$ (the $\left(\mathrm{ClO}_{4}\right)_{2}$ salt) differ in terms of the solvents (methanol and water, respectively) used for the reaction and recrystallisation, we examined the effects of solvents and counter anions on their crystallisation behaviour. First, the $\mathrm{Cl}\left(\mathrm{ClO}_{4}\right)$ salt (2) was recrystallised from water, which was confirmed the deposition of the same salt $\mathbf{2}$. Then, in order to complete the anion exchange, crystals of $\mathbf{2}$ were dissolved in methanol and the solution was mixed with a stoichiometric amount of $\mathrm{AgClO}_{4}$. The resulting white precipitate of $\mathrm{AgCl}$ was filtered off and the filtrate was concentrated at ambient conditions to deposit single crystals of the $\left(\mathrm{ClO}_{4}\right)_{2}$ salt. SC-XRD analysis of the product (Table S2 and Fig. S5) confirmed that the obtained crystals were the hemihydrate $\mathbf{2 A}$-identical to the crystals reported by Gütlich et al. ${ }^{22}$ These results suggest that the existence of $\mathrm{Cl}^{-}$anion is crucial for the chemical composition and crystal structure of the resulting product.

In the crystal structures of $\mathbf{2}$ and $\mathbf{2 A}$, both containing the complex cation of $\left[\mathrm{Fe}\left(\mathrm{H}_{3} \mathrm{~L}\right)\right]^{2+}$, the structural parameters in the complex cation are all similar (Table S3); they are indicative of the low-spin Fe" state at the measured temperature (193 K), which is consistent with the result of magnetic susceptibility measurement. Both compounds exhibited a characteristic intermolecular hydrogen-bonding network in the crystal structures. In the crystal of $\mathbf{2}$ (Fig. 3), three imidazole $\mathrm{N}-\mathrm{H}$ groups of the tripodal $\mathrm{H}_{3} \mathrm{~L}$ ligand in a complex cation are hydrogen-bonded to a respective $\mathrm{Cl}^{-}$anion and one of three imidazole $\mathrm{N}-\mathrm{H}$ groups is also weakly interacted with the $\mathrm{O}$ atom of the counter $\mathrm{ClO}_{4}^{-}$anion (Table S4). The $\mathrm{Cl}^{-}$anion is surrounded by three $\left[\mathrm{Fe}\left(\mathrm{H}_{3} \mathrm{~L}\right)\right]^{2+}$ complex cations, by the abovementioned $\mathrm{N}-\mathrm{H} \cdots \mathrm{Cl}$ hydrogen bonds, together with the other three $\left[\mathrm{Fe}\left(\mathrm{H}_{3} \mathrm{~L}\right)\right]^{2+}$ cations having weak $\mathrm{C}($ imine $)-\mathrm{H} \cdots \mathrm{Cl}$ interaction (Fig. 4), hence forming a three-dimensional (3D) network structure. In contrast, in the crystal structure of $\mathbf{2 A}$, three imidazole $\mathrm{N}-\mathrm{H}$ groups in the complex cation were hydrogen-bonded to a respective perchlorate anion and a water molecule of crystallisation (Fig. S6). These hydrogen-bonding interactions form a two-dimensional (2D) sheet structure. 


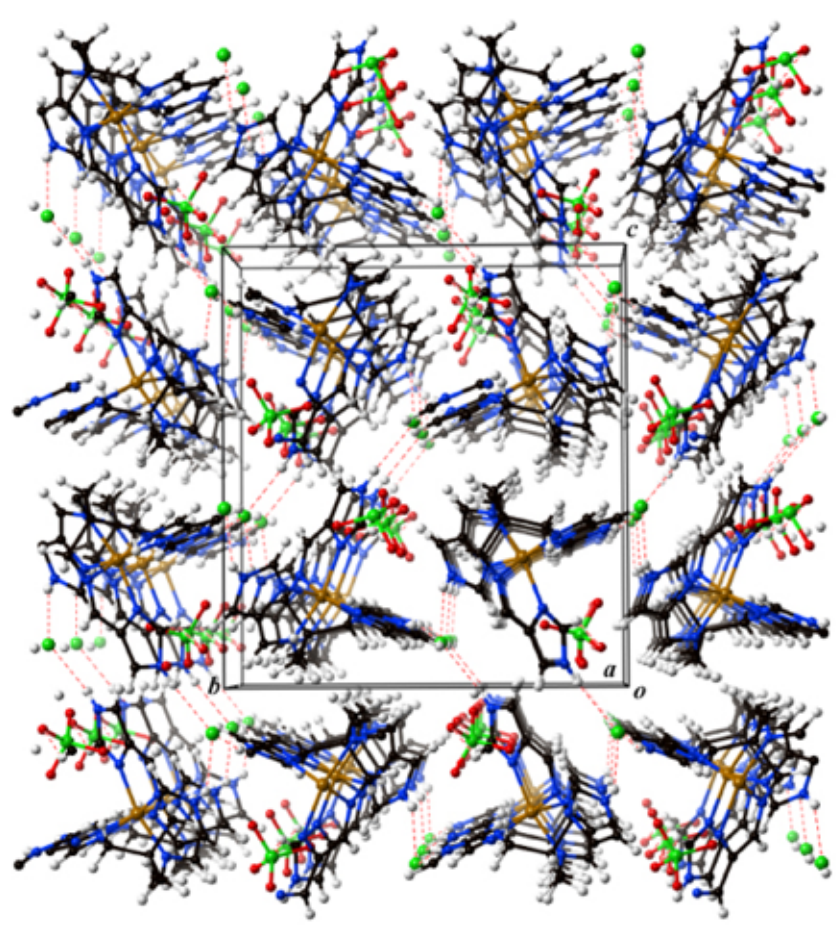

Fig. 3 A packing diagram of $\left[\mathrm{Fe}\left(\mathrm{H}_{3} \mathrm{~L}\right)\right] \mathrm{Cl}\left(\mathrm{ClO}_{4}\right)(2)$ viewed along the $a$ axis (red dashed lines indicate possible hydrogen bonds).

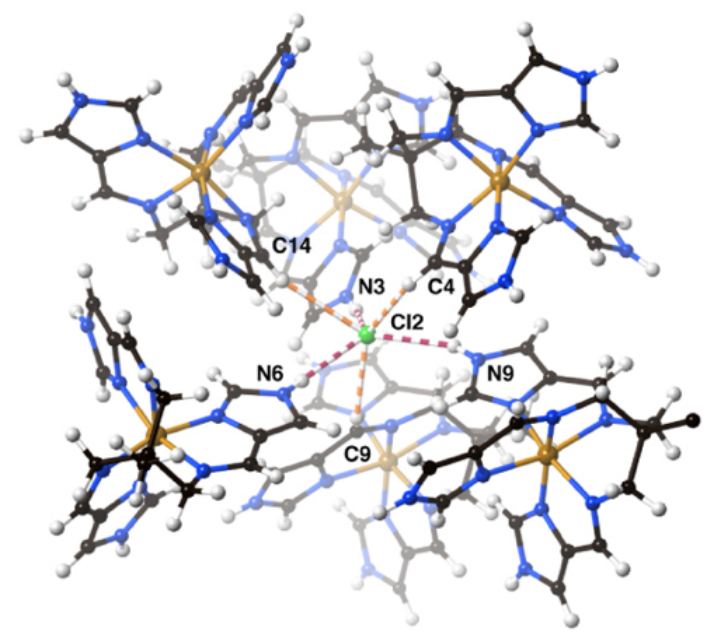

Fig. 4 A perspective view of the surrounding of the $\mathrm{Cl}^{-}$anion in 2: three hydrogen bonds (red dashed cylinder) and three possible $\mathrm{C}-\mathrm{H} \cdots \mathrm{Cl}$ interactions (orange dashed cylinder).

Compounds $\mathbf{1}$ and 3-5 are isomorphous with compound 2; this indicates that a similar 3D hydrogen-bonding network is formed due to the presence of a $\mathrm{Cl}^{-}$anion (Table S4). Therefore, the hydrogen bonds between the imidazole $\mathrm{N}-\mathrm{H}$ groups and $\mathrm{Cl}^{-}$ anions (i.e., Fig. 4) could be a key factor in the spontaneous resolution (i.e., homochiral aggregation) of these compounds.

\section{Circular dichroism spectra of single crystals}

Compounds 1-5 exhibited spontaneous resolution, as indicated by their non-enantiogenic space group. To confirm the resolution of enantiomers, we measured solid-state $C D$ spectra using single crystals of suitable size. However, because the Co" complex $\left[\mathrm{Co}\left(\mathrm{H}_{3} \mathrm{~L}\right)\right] \mathrm{Cl}\left(\mathrm{ClO}_{4}\right)(3)$ is easily oxidized in air, it was not included in our measurements; we only recorded spectra of the complexes 1, 2, 4 and $\mathbf{5}$.

In solution, compounds 1-5 (except $\mathbf{3}$ ) did not show any Cotton effect (CD signal), even if a sample solution was prepared by dissolving a single-crystal resolved spontaneously (Fig. S7). This means that racemisation, due to reversion of the twist of tripodal ligand arms, takes place quickly in solution at ambient temperature.

We then measured solid-state CD spectra of samples using a transparent $\mathrm{KBr}$ disk (prepared by a standard method for IR spectral measurement). ${ }^{4 a, b}$ First, we selected 10 pieces of large single crystals from one batch of recrystallisation of each compound, and prepared 10 disks using a respective crystal. As the sizes of the single crystals that we used were random and the thickness of the disk was not uniform, the CD intensity would be arbitrary (i.e., the results would only be qualitative). Nonetheless, the observed CD intensities (Fig. 5) were strong enough (after sample blank correction, measured with a blank $\mathrm{KBr}$ disk). We then further checked the $\mathrm{CD}$ spectra by reversing or rotating the disk; no significant effects on the spectra were observed. We therefore concluded that the observed $C D$ signals resulted from the solid sample of each compound. (a)

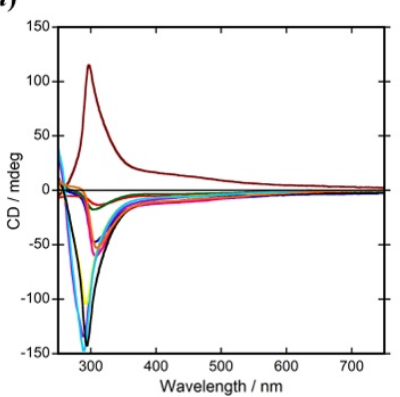

(c)

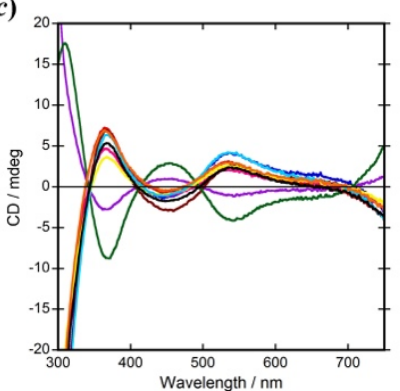

(b)

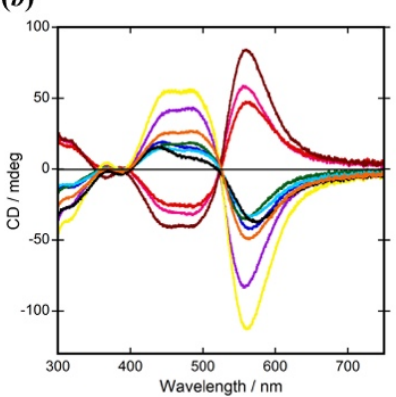

(d)

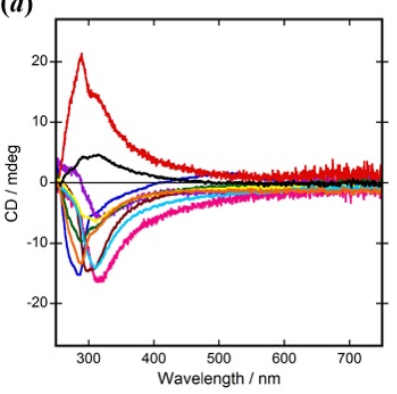

Fig. 5 Observed solid-state $C D$ spectra of $10 \mathrm{KBr}$ sample disks, each of which was prepared from a single-crystal deposited in one batch of recrystallisation of $(a)$ $\left[\mathrm{Mn}\left(\mathrm{H}_{3} \mathrm{~L}\right)\right] \mathrm{Cl}\left(\mathrm{ClO}_{4}\right) \quad(1), \quad(b) \quad\left[\mathrm{Fe}\left(\mathrm{H}_{3} \mathrm{~L}\right)\right] \mathrm{Cl}\left(\mathrm{ClO}_{4}\right) \quad(2), \quad(c) \quad\left[\mathrm{Ni}\left(\mathrm{H}_{3} \mathrm{~L}\right)\right] \mathrm{Cl}\left(\mathrm{ClO}_{4}\right)$ (4) and (d) $\left[\mathrm{Zn}\left(\mathrm{H}_{3} \mathrm{~L}\right)\right] \mathrm{Cl}\left(\mathrm{ClO}_{4}\right)(\mathbf{5})$.

Because compounds 1-5 exhibit spontaneous resolution, each sample would give an either positive or negative Cotton effect in the CD spectrum. When a "normal" spontaneous resolution takes place, it would be expected that a number of samples (single-crystals) obtained in one batch of recrystallisation would give a pair of symmetrical CD spectra in a nearly $1: 1$ ratio (Fig. 6 b upper). When a "total spontaneous resolution" (Fig. 1) takes place, all samples measured using this method would give the same Cotton effect (Fig. 6c upper). In the observed spectra (Fig. 5), both positive and negative Cotton 
effects were observed for all compounds, which suggested that, at least, a total spontaneous resolution had not been achieved in these compounds. It should be noted, however, that for each compound for which 10 measurements were recorded the enantiomeric spectra were not observed in an equal probability. The actual ratios of both enantiomeric spectra of a specific recrystallisation experiment shown in Fig. 5 were 9:1 (for 1), 7:3 (for 2), 8:2 (for 4 ) and 8:2 (for 5). These results suggested that an imbalanced formation of enantiomorphic crystals resulted, i.e., the ratios of appearance between the left-handed ( $\Lambda$-form) and the right-handed ( $\Delta$-form) complex cations were not equal to unity $(1: 1)$.

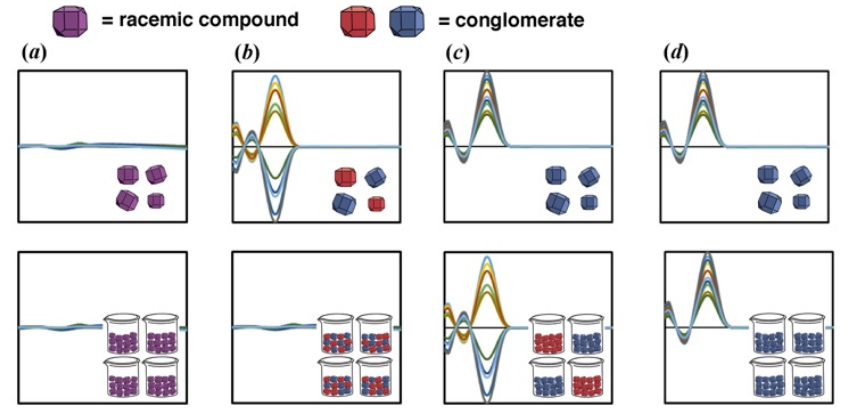

Fig. 6 The schematic and expected $C D$ spectral patterns (upper) for the $\mathrm{KBr}$ sample disks prepared from a single-crystal obtained in one batch of recrystallisation and (lower) for those prepared from all bulk microcrystals obtained in several recrystallisation experiments in the cases of $(a)$ racemic compound crystallisation, $(b)$ normal spontaneous resolution, $(c)$ total spontaneous resolution and $(d)$ absolute spontaneous resolution.

\section{Circular dichroism spectra of bulk crystalline samples}

The enantiomeric imbalance in the single crystals (addressed above) might be complained as the results of accidental pick-up of the enantiomorphic crystals unequally. To confirm our hypothesis for imbalanced formation of both enantiomorphic crystals (i.e., enantiomeric complex cations), we designed a further experiment in which all bulk crystalline samples were collected together and then used for preparation of a $\mathrm{KBr}$ disk for solid-state CD measurement. In this case, we did not need to grow large single crystals; we tried to obtain microcrystals of uniform size and quality. It was, however, necessary to confirm whether the microcrystals thus obtained had the same crystal structure as derived from single-crystal X-ray analysis, i.e., phase purity. The PXRD patterns measured for all microcrystalline samples of 1-5 (except $\mathbf{3}$ ) were consistent with the simulated patterns from the crystal structures analysed by single-crystal X-ray diffraction (Fig. S8). This suggested that all bulk samples have the same crystal structures.

When we measure the solid-state $\mathrm{CD}$ spectrum with the $\mathrm{KBr}$ sample disk prepared from all bulk microcrystals obtained in a recrystallisation experiment repeatedly (at least 10 times), a pair of enantiomeric spectra (with positive and negative Cotton effects) will be observed if imbalanced formation of enantiomorphic crystals always occurs. On the other hand, in the case that a normal spontaneous resolution takes place, no or negligible Cotton effect will be observed (Fig. 6, lower). The actual results for complex 2 are shown in Fig. 7b, as an example; a clear Cotton effect was observed in each measurement. In addition, symmetrical CD spectra were unambiguously observed. This indicated that imbalanced formation of enantiomorphic crystals actually took place in every recrystallisation experiments, but the preferential enantiomers (enantiomorphic crystals) obtained would be altered by the respective recrystallisation. Hence, we could state that incomplete total spontaneous resolution (Fig. 8) was observed in this case. (a)

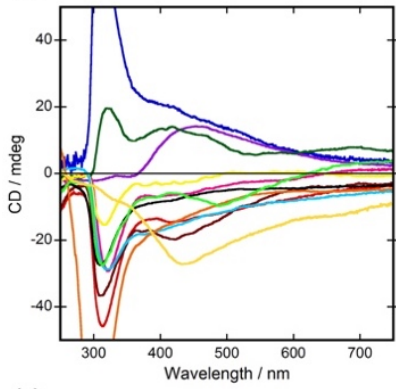

(c)

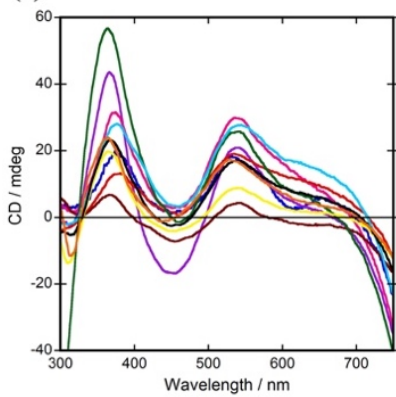

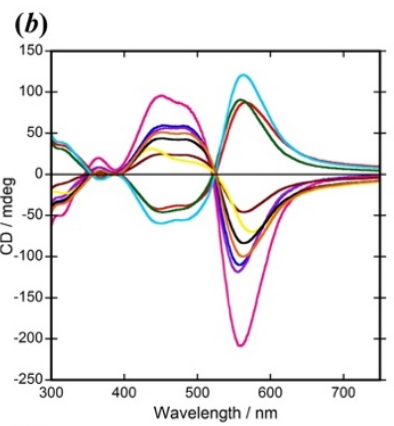

(d)

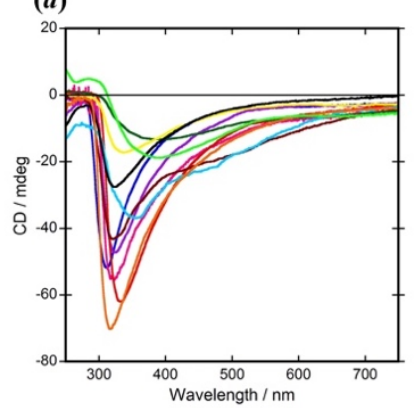

Fig. 7 Observed solid-state CD spectra of at least $10 \mathrm{KBr}$ sample disks, each of which was prepared from all bulk crystalline products obtained in a recrystallization experiment, of (a) $\left[\mathrm{Mn}\left(\mathrm{H}_{3} \mathrm{~L}\right)\right] \mathrm{Cl}\left(\mathrm{ClO}_{4}\right)$ (1), (b) $\left[\mathrm{Fe}\left(\mathrm{H}_{3} \mathrm{~L}\right)\right] \mathrm{Cl}\left(\mathrm{ClO}_{4}\right)$ (2), (c) $\left[\mathrm{Ni}\left(\mathrm{H}_{3} \mathrm{~L}\right)\right] \mathrm{Cl}\left(\mathrm{ClO} \mathrm{O}_{4}\right)$ (4) and (d) $\left[\mathrm{Zn}\left(\mathrm{H}_{3} \mathrm{~L}\right)\right] \mathrm{Cl}\left(\mathrm{ClO}_{4}\right)(5)$.

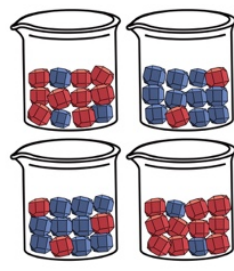

incomplete total spontaneous resolution

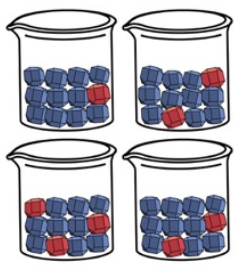

incomplete absolute spontaneous resolution
Fig. 8 Proposed phenomena of crystallization of complexes 1-5: incomplete total or absolute spontaneous resolution.

The results for compounds $\mathbf{1}, \mathbf{4}$ and $\mathbf{5}$ are also shown in Fig. 7. In the case of the $\mathrm{Mn}^{\prime \prime}$ compound (1), a similar result to the abovementioned $\mathrm{Fe}^{\prime \prime}$ compound (2) was observed, i.e., an incomplete total spontaneous resolution was suggested. On the other hand, in the cases of the $\mathrm{Ni}^{\prime \prime}$ and $\mathrm{Zn}$ " compounds (4 and $\mathbf{5}$ ) all spectra exhibited the same Cotton effect (although there was variation in $C D$ intensities). This suggested that even the total spontaneous resolution was not achieved, but a specific enantiomer (enantiomorphic crystal) was always formed preferentially upon crystallisation (i.e., incomplete absolute 
spontaneous resolution: Fig. 8). In the other words, there would be a certain (but as yet unknown) factor that affects the predominant deposition of either enantiomorphic crystal when spontaneous resolution takes place from a solution of a racemic mixture in which rapid racemisation occurs. These phenomenon that we observed in this study may indicate the production of chirality from a system in which no chiral components exist. ${ }^{25,26}$

\section{Conclusions}

The tripodal hexadentate ligand $\mathrm{H}_{3} \mathrm{~L}$, derived from the reaction of tame $\bullet 3 \mathrm{HCl}$, triethylamine, and 4-formylimidazole, formed mononuclear complexes with $\mathrm{Mn}^{\prime \prime}, \mathrm{Fe}^{\prime \prime}, \mathrm{Co}^{\prime \prime}, \mathrm{Ni}^{\prime \prime}$ and $\mathrm{Zn}^{\prime \prime}$ ions: $\left[\mathrm{M}\left(\mathrm{H}_{3} \mathrm{~L}\right)\right] \mathrm{Cl}\left(\mathrm{ClO}_{4}\right)(\mathbf{1 - 5})$. These compounds crystallised in an isomorphic and non-enentiogenic space group, $P 2{ }_{1} 2_{1} 2_{1}$ with $Z=$ 4 , which is indicative of spontaneous resolution of the compounds. The complex cations are chiral due to the synchronous twist of three arms of the ligand, and the hydrogen-bonding interaction between the imidazole $\mathrm{N}-\mathrm{H}$ donor and the chloride anion forms a 3D hydrogen-bonding network, which would induce the homochiral aggregation of the complex cations.

Solid-state CD spectra of single-crystals deposited after recrystallisation also indicated the spontaneous resolution. Interestingly, an imbalance was observed in the number of appearances of the enantiomorphic crystals, and the imbalanced formation of the enantiomers was also confirmed by the CD spectra of all bulk crystalline samples deposited in a recrystallisation experiment. It is concluded that the formation ratios of the enantiomorphic crystals were not equal to unity in all cases. Moreover, in the cases of $\mathrm{Ni}^{\mathrm{II}}$ and $\mathrm{Zn}$ " compounds results of some experiments (involving recrystallisation and $C D$ measurements) indicated that the enantiomorphic deviation was always in the same direction; the CD spectra of all bulk samples always exhibited the same Cotton effect.

We propose an incomplete total spontaneous resolution for crystallisation of the $\mathrm{Mn}^{\mathrm{I}}$ and $\mathrm{Fe}^{\mathrm{I}}$ compounds ( $\mathbf{1}$ and $\mathbf{2}$ ) and an incomplete absolute spontaneous resolution for crystallisation of the $\mathrm{Ni}$ " and $\mathrm{Zn}$ " compounds (4 and 5) (Fig. 8).

\section{Experimental}

All chemicals and solvents were reagent grade and used as received.

\section{Preparation of the ligand}

A tripodal triamine, 1,1,1-tris(aminomethyl)ethane (tame), was prepared by a method described in literature. ${ }^{27}$ This triamine (a yellow oil) reacts readily with aqueous moisture and carbon dioxide to afford the carbonate salt. It was therefore isolated and stored as the chloride salt (tame $\bullet 3 \mathrm{HCl}$ ) after reaction with excess aqueous $\mathrm{HCl}$. A methanol solution $(10 \mathrm{~mL})$ containing tame $\cdot 3 \mathrm{HCl}(0.045 \mathrm{~g}, 0.20 \mathrm{mmol})$ and a stoichiometric amount ( $0.60 \mathrm{mmol})$ of $\mathrm{NEt}_{3}$ was added to a methanol solution $(10 \mathrm{~mL})$ of 4-formylimidazole $(0.058 \mathrm{~g}, 0.60 \mathrm{mmol})$ and the mixture was heated, with stirring, at $50{ }^{\circ} \mathrm{C}$ for $1 \mathrm{~h}$. The resulting pale yellow solution (containing $\mathrm{H}_{3} \mathrm{~L}$ ) was used for the preparation of the following complexes.

\section{Preparation of transition-metal(II) complexes}

$\left[\mathrm{Mn}\left(\mathrm{H}_{3} \mathrm{~L}\right)\right] \mathrm{Cl}\left(\mathrm{ClO}_{4}\right)$ (1). A methanol solution $(20 \mathrm{~mL})$ of $\mathrm{Mn}\left(\mathrm{ClO}_{4}\right)_{2} \bullet 6 \mathrm{H}_{2} \mathrm{O}(0.072 \mathrm{~g}, 0.20 \mathrm{mmol})$ was added to a solution $(0.20$ mmol) of the abovementioned ligand $\mathrm{H}_{3} \mathrm{~L}$ in methanol $(20 \mathrm{~mL})$ and the mixture was stirred at room temperature for several hours. A pale yellow precipitate of compound $\mathbf{1}$ was obtained and collected by filtration. Recrystallization of the crude product from methanol by slow evaporation of the solvent at ambient temperature afforded pale yellow crystals of 1. Yield: $0.092 \mathrm{~g}(85 \%)$. Anal. Calcd for $\mathrm{C}_{17} \mathrm{H}_{21} \mathrm{Cl}_{2} \mathrm{MnN}_{9} \mathrm{O}_{4}$ : C, 37.72; $\mathrm{H}, 3.91 ; \mathrm{N}, 23.29 \%$. Found: C, 37.83; $\mathrm{H}, 3.69 ; \mathrm{N}, 23.21 \%$.

$\left[\mathrm{Fe}\left(\mathrm{H}_{3} \mathrm{~L}\right)\right] \mathrm{Cl}\left(\mathrm{ClO}_{4}\right)$ (2). This compound was prepared by a similar method to the above, using $\mathrm{Fe}\left(\mathrm{ClO}_{4}\right)_{2} \bullet 6 \mathrm{H}_{2} \mathrm{O}$. Recrystallization of the crude product from methanol afforded red crystals of 2 in $71 \%$ yield. Anal. Calcd for $\mathrm{C}_{17} \mathrm{H}_{21} \mathrm{Cl}_{2} \mathrm{FeN}_{9} \mathrm{O}_{4}: \mathrm{C}, 37.66 ; \mathrm{H}, 3.90 ; \mathrm{N}, 23.25 \%$. Found: $\mathrm{C}, 37.54 ; \mathrm{H}, 3.76 ; \mathrm{N}, 22.78 \%$. Attempt to recrystallize this complex salt from hot water afforded the same crystals of $\mathbf{2}$. The crystal structure was confirmed by single-crystal X-ray diffraction.

$\left[\mathrm{Fe}\left(\mathrm{H}_{3} \mathrm{~L}\right)\right]\left(\mathrm{ClO}_{4}\right)_{2} \cdot \mathbf{0 . 5} \mathrm{H}_{2} \mathrm{O}(2 \mathrm{~A})$. A methanol solution $(200 \mathrm{~mL})$ of 2 $(0.054 \mathrm{~g}, 0.10 \mathrm{mmol})$ was mixed with a methanol solution $(10 \mathrm{~mL})$ of $\mathrm{AgClO}_{4}(0.021 \mathrm{~g}, 0.10 \mathrm{mmol})$ and stirred in the dark at ambient temperature overnight. The resulting white precipitate of $\mathrm{AgCl}$ was filtered off (using a membrane filter). The filtrate was evaporated at ambient conditions to afford red crystals of compound 2A. Yield: $0.032 \mathrm{~g}(52 \%)$. Anal. Calcd for $\mathrm{C}_{18} \mathrm{H}_{23} \mathrm{Cl}_{2} \mathrm{FeN}_{9} \mathrm{O}_{8.5}: \mathrm{C}, 33.19 ; \mathrm{H}, 3.60$; N, 20.49\%. Found: C, 33.07; H, 3.50; N, 20.31\%.

$\left[\mathrm{Co}\left(\mathrm{H}_{3} \mathrm{~L}\right)\right] \mathrm{Cl}\left(\mathrm{ClO}_{4}\right)(3)$. This compound was prepared by a method similar to that used to prepare complexes $\mathbf{1}$ and $\mathbf{2}$, using $\mathrm{Co}\left(\mathrm{ClO}_{4}\right)_{2} \bullet 6 \mathrm{H}_{2} \mathrm{O}$. The reaction was carried out under a nitrogen atmosphere. Brown crystals of $\mathbf{3}$ were obtained in $70 \%$ yield. Anal. Calcd for $\mathrm{C}_{17} \mathrm{H}_{21} \mathrm{Cl}_{2} \mathrm{~N}_{9} \mathrm{NiO}_{4}$ : C, 37.45; $\mathrm{H}, 3.88 ; \mathrm{N}, 23.12 \%$. Found: $\mathrm{C}$, 37.33; H, 3.96; N, 22.91\%.

$\left[\mathrm{Ni}\left(\mathrm{H}_{3} \mathrm{~L}\right)\right] \mathrm{Cl}\left(\mathrm{ClO}_{4}\right)(4)$. This compound was prepared by a method similar to that used to prepare complexes $\mathbf{1}$ and $\mathbf{2}$, using $\mathrm{Ni}\left(\mathrm{ClO}_{4}\right)_{2} \cdot 6 \mathrm{H}_{2} \mathrm{O}$. Purple crystals of 4 were obtained in $69 \%$ yield. Anal. Calcd for $\mathrm{C}_{17} \mathrm{H}_{21} \mathrm{Cl}_{2} \mathrm{~N}_{9} \mathrm{NiO}_{4}: \mathrm{C}, 37.46 ; \mathrm{H}, 3.88 ; \mathrm{N}, 23.13 \%$. Found: C, 37.08; $\mathrm{H}, 4.18 ; \mathrm{N}, 22.64 \%$.

$\left[\mathrm{Zn}\left(\mathrm{H}_{3} \mathrm{~L}\right)\right] \mathrm{Cl}\left(\mathrm{ClO}_{4}\right)(5)$. This compound was prepared by a method similar to that used to prepare complexes $\mathbf{1}, \mathbf{2}$ and $\mathbf{4}$, using $\mathrm{Zn}\left(\mathrm{ClO}_{4}\right)_{2} \bullet 6 \mathrm{H}_{2} \mathrm{O}$. Colourless crystals or white microcrystals of $\mathbf{5}$ were obtained in $86 \%$ yield. Anal. Calcd for $\mathrm{C}_{17} \mathrm{H}_{21} \mathrm{Cl}_{2} \mathrm{~N}_{9} \mathrm{O}_{4} \mathrm{Zn}$ : C, 37.01; $\mathrm{H}$, $3.84 ; \mathrm{N}, 22.85 \%$. Found: $\mathrm{C}, 36.92 ; \mathrm{H}, 3.85 ; \mathrm{N}, 22.70 \%$.

\section{Elemental analysis and physical measurements}


Elemental analysis was performed at the Division of Instrumental Analysis, Advanced Science Research Center, Okayama University. The temperature dependence (1.9-300 K) of magnetic susceptibility data were measured using an MPMS XL5 SQUID magnetometer under an external magnetic field of $0.1 \mathrm{~T}$. Infrared spectra were recorded on a Jasco FT/IR FT-001 spectrophotometer with the samples prepared as $\mathrm{KBr}$ disks. UV-vis absorption spectra and CD spectra in methanol were obtained on a Jasco V-550 spectrophotometer and Jasco J-720 spectropolarimeter, respectively, at room temperature.

\section{Crystallography}

The PXRD data were collected on a Rigaku RINT-TTR III diffractometer at room temperature.

The SC-XRD data were collected on a Rigaku R-AXIS rapid diffractometer equipped with an imaging plate area detector or a Rigaku VariMax diffractometer with a Saturn CCD detector. Graphite or multilayered mirror monochromated Mo $\mathrm{K} \alpha$ radiation ( $\lambda=0.71075 \AA$ ) was used as the X-ray source. A suitable single crystal was picked up with a cryoloop from paraffin oil and flash cooled in a cold nitrogen gas stream. The diffraction data were processed using the Process-Auto ${ }^{28}$ or the CrystalClear $^{29}$ software packages, and the numerical absorption corrections ${ }^{30}$ were applied. The structures were solved using a direct method, employing the SIR $2008^{31}$ or SIR $2011^{32}$ software packages, and refined on $F^{2}$ (with all independent reflections) using the SHELXL2014 ${ }^{33}$ software package. All non-hydrogen atoms were refined anisotropically. Hydrogen atoms were introduced at the theoretical positions and refined using riding models. Absolute configurations of the crystals 1-5 used for the XRD analysis were established by anomalous-dispersion effects in diffraction measurements (i.e., using the Flack parameter). All calculations were carried out using the CrystalStructure software package. ${ }^{34}$

\section{Solid-state CD measurement}

The solid-state CD spectra were measured on a JASCO J-720 spectropolarimeter (spectra collected in transmittance mode) using $\mathrm{KBr}$ disks of samples. A disk was prepared from a single piece of crystal or an entire batch of microcrystals of the compound with crystalline $\mathrm{KBr}$, according to the following procedure. A mixture of sample and $\mathrm{KBr}$ was well ground in an agate mortar then vacuum pressed to form a uniform disk. The disk was placed in a sample holder, which was then positioned in the cell holder of the spectropolarimeter (see Fig. S9). For each disk, the $C D$ signals were measured from both sides, then the average was taken. A blank disk was used to measure background spectra. The data were corrected accordingly.

\section{Conflicts of interest}

There are no conflicts to declare.

\section{Acknowledgements}

This work was supported by JSPS KAKENHI Grant Numbers 23655052 and $18 K 05146$.

\section{Notes and references}

1 (a) H. D. Flack, Acta Crystallogr., Sect. A, 2009, 65, 371. (b) L. Addadi, Z. Berkovitch-Yellin, N. Domb, E. Gati, M. Lahav and L. Leiserowitz, Nature, 1982, 296, 21.

2 D. K. Kondeoudi, R. J. Kaufman and N. Singh, Science, 1990, 250, 975.

3 R. R. E. Steendam, T. J. B. van Benthem, E. M. E. Huijs, H. Meekes, W. J. P. van Enckevort, J. Raap, F. P. J. T. Rutjes and E. Vlieg, Cryst. Growth Des., 2015, 15, 3917.

4 (a) A. Lennartson and M. Håkansson, Angew. Chem. Int. Ed., 2009, 48, 5869; (b) A. Johansson, M. Håkansson and S. Jagner, Chem. Eur. J., 2005, 21, 5311. (c) A. Lennartson, A. Hedström and M. Hakansson, Organometallics, 2010, 29, 177. (d) A. Pettersen, A. Lennartson and M. Hakansson, Organometallics, 2009, 28, 3567.

5 (a) F. Yagishita, H. Ishikawa, T. Onuki, S. Hachiya, T. Mino and M. Sakamoto, Angew. Chem. Int. Ed., 2012, 51, 13023; (b) I. D. Cunningham, S. J. Coles and M. B. Hursthouse, Chem. Commun., 2000, 61.

6 G. Brewer, C. Brewer, R. J. Butcher, G. T. Robichaux and C. Viragh, Inorg. Chim. Acta, 2014, 410, 171.

7 C. Viedma, and P. Cintas, Chem. Commun., 2011, 47, 12786.

8 (a) J. E. Hein, B. H. Cao, C. Viedma, R. M. Kellogg and D. G. Blackmond, J. Am. Chem. Soc., 2012, 134, 12629; (b) C. Viedma, Phys. Rev. Lett., 2005, 94, 065504.

9 (a) W. L. Noorduin, E. Vlieg, R. M. Kellogg and B. Kaptein, Angew. Chem. Int. Ed., 2008, 47, 9600; (b) W. J. Noorduin, H. Meekes, A. A. C. Bode, W. J. P. van Enckevort, B. Kaptein, R. M. Kellogg and E. Vlieg, Cryst. Growth Des., 2008, 8, 1675; (c) W. L. Noorduin, T. Izumi, A. Millemaggi, M. Leeman, H. Meekes, W. J. P. van Enckevort, R. M. Kellogg, B. Kaptein, E. Vlieg and D. G. Blackmond, J. Am. Chem. Soc., 2008, 130, 1158; (d) W. L. Noorduin, W. J. P. van Enckevort, H. Meekes, B. Kaptein, R. M. Kellogg, J. C. Tully, J. M. McBride and E. Vlieg, Angew. Chem. Int. Ed., 2010, 49, 8435.

10 (a) R. R. E. Steendam, J. M. M. Verkade, T. J. B. van Benthem, H. Meekes, W. J. P. van Enckevort, J. Raap, F. P. J. T. Rutjes and E. Vlieg, Nat. Commun., 2014, 5, 5543; (b) L.-C. Sögütoglu, R. R. E. Steendam, H. Meekes, E. Vlieg and F. P. J. T. Rutjes, Chem. Soc. Rev., 2015, 44, 6723.

11 H. Zhang, P. Lin, X. Shan, L. Han and S. Du, CrystEngComm 2014, 16, 1245.

12 A. M. McDaniel, A. K. Rappé and M. P. Shores, Inorg. Chem., 2012, 51, 12493.

13 (a) G. Brewer, C. Luckett, L. May, A. M. Beatty and W. R. Scheidt, Inorg. Chim. Acta, 2004, 357, 2390; (b) C. Brewer, G. Brewer, R. J. Butcher, E. E. Carpenter, L. Cuenca, B. C. Noll, W. R. Scheidt, C. Viragh, P. Y. Zavalij and D. Zielask, Dalton Trans., 2006, 1009.

14 S.-P. Yang, Y.-X. Tong, H.-L. Zhu, H. Cao, X.-M. Chen and L.-N Ji, Polyhedron, 2001, 20, 223.

15 (a) Y. Sunatsuki, H. Ohta, M. Kojima, Y. Ikuta, Y. Goto, N. Matsumoto, S. lijima, H. Akashi, S. Kaizaki, F. Dahan and J.-P. Tuchagues, Inorg. Chem., 2004, 43, 4154; (b) I. Katsuki, Y. Motoda, Y. Sunatsuki, N. Matsumoto, T. Nagashima and M. Kojima, J. Am. Chem. Soc., 2002, 124, 629; (c) T. Yamaguchi, K. Harada, Y. Sunatsuki, M. Kojima, K. Nakajima and N. Matsumoto, Eur. J. Inorg. Chem., 2006, 3236.

16 F. Reichel, J. K. Clegg, K. Gloe, K. Gloe, J. J. Weigand, J. K. Reynolds, C.-G. Li, J. R. Aldrich-Wright, C. J. Kepert, L. F. Lindoy, H.-C. Yao and F. Li, Inorg. Chem., 2014, 53, 688.

17 (a) S. Nagasato, Y. Sunatsuki, S. Ohsato, T. Kido, N. Matsumoto and M. Kojima, Chem Commun., 2002, 14; (b) H. Nakamura, Y. 
Sunatsuki, M. Kojima and N, Matsumoto, Inorg. Chem., 2007, 46, 8170.

18 M. Figuet, M. T. Averbuch-Pouchot, A. du M. d'Hardemare and O. Jarjayes, Eur. J. Inorg. Chem., 2001, 2089.

19 (a) T. Yamaguchi, J.-P. Costes, Y. Kishima, M. Kojima, Y. Sunatsuki, N. Bréfuel, J.-P. Tuchagues, L. Vendier and W. Wernsdorfer, Inorg. Chem., 2010, 49, 9125; (b) Y. Sunatsuki, Y. Kishima, T. Kobayashi, T. Yamaguchi, T. Suzuki, M. Kojima, J. Krzystek and M. R. Sundberg, Chem. Commun., 2011, 47, 9149.

20 (a) T. Yamaguchi, Y. Sunatsuki, H. Ishida, M. Kojima, H. Akashi, N. Re, N. Matsumoto, A. Pochaba and J. Mrozinski, Inorg. Chem., 2008, 47, 5736; (b) T. Yamaguchi, Y. Sunatsuki, H. Ishida, M. Kojima, H. Akashi, N. Re, N. Matsumoto, A. Pochaba and J. Mrozinski, Bull. Chem. Soc. Jpn., 2008, 81, 598; (c) T. Kobayashi, T. Yamaguchi, H. Ohta, Y. Sunatsuki, M. Kojima, N. Re, M. Nonoyama and N. Matsumoto, Chem. Commun., 2006, 1950; (d) T. Yamaguchi, Y. Sunatsuki, M. Kojima, H. Akashi, M. Tsuchimoto, N. Re, S. Osa and N. Matsumoto, Chem. Commun., 2004, 1048.

21 J.-Y. Ge, Z. Chen, Y.-R. Qiu, D. Huo, Y.-Q. Zhang, P. Wang and J.-L. Zuo, Inorg. Chem., 2019, 58, 9387.

22 M. Seredyuk, A. B. Gaspar, J. Kusz and P. Gütlich, Z. Anorg. Alle. Chem., 2011, 637, 965.

23 F. Matyuska, A. Szorcsik, N. V. May, Á. Dancs, É. Kováts, A. Bényei and T. Gajda, Dalton Trans., 2017, 46, 8626.

24 (a) M. Nespolo, Cryst. Res. Techn., 2015, 50, 413; (b) E. Pidcock, Chem. Commun., 2005, 3457.

25 C.-Y. Gao, F. Wang, H.-R. Tian, L.-J. Li, J. Zhang and Z.-M. Sun, Inorg. Chem., 2016, 55, 537.

26 K. Soai, S. Niwa and H. Hori, J. Chem. Soc., Chem. Commun., 1990, 982.

27 E. A. Fleischer, A. E. Gebala, A. Levey and P. A. Tasker, J. Org. Chem., 1971, 36, 3042.

28 Rigaku Co. Ltd., Process-Auto, Akishima, Tokyo, 1998.

29 Rigaku Co. Ltd., CrystalClear, Akishima, Tokyo, 1998-2015.

30 Rigaku Co. Ltd., NUMABS, Akishima, Tokyo, 1999.

31 M. C. Burla, R. Caliandro, M. Camalli, B. Carrozzini, G. L. Cascarano, L. De Caro, C. Giacovazzo, G. Polidori, D. Siliqi and R. Spagna, J. Appl. Cryst., 2007, 40, 609.

32 M. C. Burla, R. Caliandro, M. Camalli, B. Carrozzini, G. L. Cascarano, C. Giacovazzo, M. Mallamo, A. Mazzone, G. Polidori and R. Spagna, J. Appl. Crystallogr., 2012, 45, 357.

33 G. M. Sheldrick, Acta Cryst., 2008, A64, 112.

34 Rigaku Co. Ltd., CrystalStructure, Akishima, Tokyo, 2000-2016. 


\section{ARTICLE}

Table 1 Selected bond lengths $(\AA)$, bond angles $\left({ }^{\circ}\right)$ and torsion angles $\left({ }^{\circ}\right)$ of complexes 1-5.

\begin{tabular}{|c|c|c|c|c|c|}
\hline Parameter $^{a}$ & 1 & 2 & 3 & 4 & 5 \\
\hline$M-N(a)$ & $2.292(2), 2.278(2), 2.260(2)$ & $1.941(3), 1.951(3), 1.935(3)$ & $2.151(2), 2.146(2), 2.131(2)$ & $2.0995(19), 2.0967(18), 2.094(2)$ & $2.196(5), 2.221(4), 2.219(4)$ \\
\hline$M-N(b)$ & $2.215(2), 2.206(2), 2.217(2)$ & $1.979(3), 1.974(3), 1.990(3)$ & $2.136(2), 2.124(2), 2.131(2)$ & $2.0943(19), 2.0868(19), 2.0760(18)$ & $2.122(4), 2.119(4), 2.135(4)$ \\
\hline$C(a)-C(b)$ & $1.540(3)$ & $1.546(5)$ & $1.543(3)$ & $1.542(3)$ & $1.542(8)$ \\
\hline$c(b)-C(c)$ & $1.545(3), 1.541(3), 1.548(3)$ & $1.546(5), 1.539(5), 1.542(5)$ & $1.551(3), 1.540(3), 1.547(4)$ & $1.549(3), 1.545(3), 1.549(3)$ & $1.555(8), 1.532(7), 1.544(7)$ \\
\hline$N(a)-C(c)$ & $1.467(3), 1.468(3), 1.462(3)$ & $1.476(4), 1.460(4), 1.474(4)$ & $1.470(3), 1.464(3), 1.458(3)$ & $1.470(3), 1.464(3), 1.457(3)$ & $1.456(7), 1.457(6), 1.473(7)$ \\
\hline$N(a)-C(d)$ & $1.273(3), 1.273(3), 1.279(3)$ & $1.296(4), 1.285(5), 1.299(4)$ & $1.280(3), 1.282(3), 1.281(3)$ & $1.281(3), 1.285(3), 1.279(3)$ & $1.274(7), 1.274(6), 1.269(7)$ \\
\hline$C(d)-C(e)$ & $1.450(4), 1.464(3), 1.448(3)$ & $1.429(5), 1.424(5), 1.422(5)$ & $1.449(4), 1.453(4), 1.437(3)$ & $1.452(3), 1.452(3), 1.437(3)$ & $1.436(7), 1.454(7), 1.449(8)$ \\
\hline$N(b)-C(e)$ & $1.395(3), 1.390(3), 1.394(3)$ & $1.396(4), 1.387(5), 1.391(4)$ & $1.390(3), 1.388(3), 1.390(3)$ & $1.393(3), 1.390(3), 1.389(3)$ & $1.395(7), 1.383(7), 1.397(7)$ \\
\hline$C(e)-C(f)$ & $1.364(4), 1.366(4), 1.369(3)$ & $1.367(5), 1.362(6), 1.365(5)$ & $1.359(4), 1.374(4), 1.370(3)$ & $1.367(3), 1.372(3), 1.368(3)$ & $1.358(7), 1.365(7), 1.359(7)$ \\
\hline$N(b)-C(g)$ & $1.316(3), 1.322(3), 1.321(3)$ & $1.327(4), 1.315(4), 1.327(4)$ & $1.324(3), 1.322(3), 1.322(3)$ & $1.320(3), 1.319(3), 1.313(3)$ & $1.316(7), 1.312(7), 1.306(7)$ \\
\hline$N(c)-C(g)$ & $1.342(4), 1.349(4), 1.348(3)$ & $1.344(5), 1.349(5), 1.344(5)$ & $1.348(4), 1.350(3), 1.339(3)$ & $1.356(3), 1.347(3), 1.343(3)$ & $1.339(7), 1.346(7), 1.347(7)$ \\
\hline$N(c)-C(f)$ & $1.354(4), 1.360(4), 1.363(3)$ & $1.369(5), 1.344(6), 1.367(5)$ & $1.357(4), 1.356(4), 1.363(4)$ & $1.361(4), 1.361(4), 1.363(3)$ & $1.367(7), 1.361(7), 1.359(7)$ \\
\hline$N(a)-M-N(b)$ & $74.05(8), 74.47(7), 74.99(7)$ & $80.93(11), 81.03(13), 80.73(11)$ & $76.41(8), 77.06(8), 77.58(8)$ & $78.77(7), 78.91(7), 79.25(8)$ & $77.09(17), 76.67(17), 76.23(17)$ \\
\hline$N(a)-M-N\left(a^{\prime}\right)$ & $78.79(7), 79.23(7), 77.54(7)$ & $86.47(12), 86.84(11), 87.41(12)$ & $82.24(8), 82.78(8), 81.44(8)$ & $83.31(7), 82.60(7), 83.90(7)$ & $80.39(16), 79.78(16), 78.77(16)$ \\
\hline$N(a)-M-N\left(b^{\prime}\right)$ & $147.36(7), 149.06(8), 145.07(8)$ & $164.52(12), 163.36(12), 165.70(11)$ & $152.43(8), 155.19(8), 150.65(8)$ & $158.62(7), 160.59(7), 157.02(8)$ & $149.68(17), 153.69(16), 151.58(17)$ \\
\hline$N(a)-M-N\left(b^{\prime \prime}\right)$ & $111.41(7), 114.03(7), 114.71(8)$ & $100.73(12), 102.05(12), 102.60(12)$ & $109.32(8), 112.59(8), 113.34(8)$ & $103.84(7), 106.97(7), 107.00(7)$ & $112.30(17), 111.38(16), 108.63(17)$ \\
\hline$N(b)-M-N\left(b^{\prime}\right)$ & $100.14(8), 101.13(8), 96.91(7)$ & $90.64(12), 93.42(12), 92.75(12)$ & $94.89(8), 96.90(8), 91.75(8)$ & $92.21(7), 96.80(8), 95.11(8)$ & $99.50(18), 97.79(17), 94.91(16)$ \\
\hline$C(a)-C(b)-C(c)-N(a)$ & $165.4(2), 164.0(2), 163.9(2)$ & $-162.4(3),-161.5(3),-162.5(3)$ & $-165.1(2),-164.0(2),-163.4(2)$ & $164.2(2), 163.49(19), 162.20(19)$ & $162.9(4), 162.7(5), 165.7(5)$ \\
\hline$M-N(a)-C(c)-C(b)$ & $26.4(3), 26.5(3), 29.4(3)$ & $-32.0(4),-33.5(4),-31.4(4)$ & $-27.0(3),-27.0(3),-29.8(3)$ & $28.8(3), 28.3(2), 31.5(2)$ & $31.0(6), 27.4(6), 28.3(7)$ \\
\hline$N(b)-M-N(a)-C(c)$ & $-174.0(1),-173.5(1),-174.2(1)$ & $165.6(2), 164.7(2), 163.2(2)$ & $172.4(2), 171.6(2), 171.5(1)$ & $-167.3(1),-165.7(1),-166.4(1)$ & $-171.5(3),-170.7(3),-171.5(3)$ \\
\hline
\end{tabular}

${ }^{a}$ The abbreviations of atoms are:

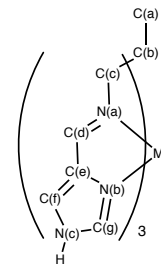

